\title{
Off-pump coronary artery bypass surgery with bilateral internal thoracic arteries: the Leipzig experience
}

\author{
Piroze M. Davierwala, Sergey Leontyev, Jens Garbade, Sven Lehmann, David Holzhey, Martin Misfeld, \\ Michael A. Borger \\ Department of Cardiac Surgery, Heart Center, University of Leipzig, Leipzig, Germany \\ Correspondence to: Dr. Piroze M. Davierwala. Heart Center, University of Leipzig, Strümpellstraße 39, 04289 Leipzig, Germany. \\ Email: pirarm@hotmail.com.
}

\begin{abstract}
Background: Contrasting results of recent randomized controlled trials (RCTs) comparing off-pump and on-pump coronary artery bypass graft (CABG) surgery, as well as the lack of evidence for any survival benefit of bilateral internal thoracic artery (ITA) grafting over single ITA use, has intensified the debate about the role of the off-pump technique and bilateral ITA use in CABG surgery. We therefore investigated our 15-year experience in off-pump CABG with bilateral ITA grafting and evaluated temporal trends in preoperative characteristics and postoperative outcomes.

Methods: Demographic, intra-operative, and outcome data of 1,199 consecutive patients undergoing offpump CABG with bilateral ITA grafting was prospectively collected in a computerized database. Patients who underwent on-pump cardiac procedures and other extra-cardiac procedures were excluded from this study. Assessment of changes in perioperative characteristics and parameters with time was performed by dividing the whole cohort into three groups (2003-2007, 2008-2012, and 2013-2017) based on the year of surgery.

Results: The overall 30-day mortality was $0.6 \%$, with no differences observed between the three time cohorts $(0.6 \%, 0.7 \%, 0.5 \% ; \mathrm{P}=0.8)$. The perioperative stroke rate for whole cohort was $0.6 \%$ and demonstrated a significant reduction in the last two time cohorts $(1 \%, 0.5 \%, 0.5 \% ; \mathrm{P}<0.0001)$. The overall incidence of deep sternal wound infections was $0.7 \%$, but was marginally higher in the last time-cohort $(0.6 \%, 0.5 \%, 0.9 \% ; \mathrm{P}=0.7)$. Overall survival for the entire cohort was $92.9 \% \pm 1 \%$ and $78.9 \% \pm 4 \%$ at 5 and 10 years follow-up, respectively. Older age at surgery and presence of peripheral vascular disease were the only predictors of late mortality.

Conclusions: Off-pump CABG with bilateral skeletonized ITAs is a safe operation and is associated with a low mortality and morbidity, which can be maintained in high volume center unit over a long period of time. The long-term survival of patients undergoing such an operation is excellent.
\end{abstract}

Keywords: Off-pump; coronary bypass; bilateral internal thoracic arteries

Submitted Apr 15, 2018. Accepted for publication May 28, 2018

doi: $10.21037 /$ acs.2018.06.15

View this article at: http://dx.doi.org/10.21037/acs.2018.06.15

\section{Introduction}

The role of off-pump coronary artery bypass graft (CABG) surgery as a method of surgical revascularization has again become the topic of intense debate in recent times, especially following the 5 -year results of two major trials comparing off-pump to on-pump CABG $(1,2)$. The Randomized On/Off Bypass (ROOBY) trial revealed lower rates of
5 -year survival and event-free survival in the off-pump CABG patients versus those on-pump (1). In contrast, the international CABG Off- or On-Pump Revascularization Study (CORONARY) showed no significant differences in the rate of the composite outcome or in the rates of the components of the outcome, including repeat coronary revascularization between patients undergoing off-pump and on-pump CABG (2). This controversy has been 
existential ever since the proponents of off-pump CABG have propagated it as a technique that reduces the risk of perioperative and long-term adverse events related to the use of cardiopulmonary bypass and aortic manipulation during on-pump CABG. It has been fueled by the conflicting results delivered by numerous small and large randomized trials that have most often been underpowered or biased (3-6).

Another point of heated discussion is whether bilateral internal thoracic arteries (ITA) truly impact long-term survival in patients undergoing CABG. The two seminal retrospective studies from the Cleveland clinic had shown that bilateral ITAs not only confer a survival benefit in patients undergoing CABG (7), but also extend this benefit further as one moves away from the time of surgery (8). Several large meta-analyses (9-11) and propensity-matched observational studies have also confirmed the benefits of bilateral ITA utilization during CABG $(12,13)$. However, the Arterial Revascularization Trial (ART), which is the only randomized controlled trial (RCT) comparing the use of single with bilateral ITA during CABG, revealed no survival benefit or reduction in the rates of cardiovascular events in favour of the latter at least till the 5 -year followup mark (14), thereby throwing the debate wide open. The investigators further performed a post hoc analysis to evaluate the differences in 1-year outcomes between onpump and off-pump CABG and reported similar rates of death and other cardiovascular events (15).

The use of bilateral ITAs in off-pump CABG further increases the complexity and the level of difficulty of CABG, especially with the use of composite grafts and sequential anastomoses. This could obviously impact the short and long-term outcomes in patients undergoing CABG. The aim of our study was, therefore, to evaluate and analyze the temporal trends in the use of bilateral ITAs in off-pump CABG over the last 15 years in our institute.

\section{Methods}

\section{Study design}

A total of 5,130 patients underwent off-pump CABG between January 2003 and December 2017 at our institution. Of these, 1,199 patients $(23.4 \%)$ received bilateral ITAs with or without additional grafts. These patients were further divided into three groups according to the year of operation (2003-2007, 2008-2012, and 20132017) in order to assess the trends in patient risk profiles and outcomes. Changes in prevalence of preoperative risk factors, intraoperative events, and operative outcomes with time were evaluated by contingency table analysis. Demographic, intra-operative, and outcome data were collected prospectively in a computerized database on all patients included in this study. Patients who underwent on-pump cardiac procedures and other concomitant extracardiac procedures such as carotid endarterectomy or planned peripheral vascular surgery were excluded from this study. Patients, who had to be converted intraoperatively to an on-pump procedure, were also excluded from the study.

\section{Outcome and explanatory variables}

The main outcomes of interest in this study were temporal trends in immediate postoperative outcomes such as 30-day mortality, postoperative cerebrovascular accidents (CVA), and deep sternal wound infections, as well as overall longterm survival. CVA was defined as the development of new focal or global neurological deficit, either permanent or transient, in the perioperative period, diagnosed clinically and confirmed by computed tomographic brain scans. Postoperative myocardial infarction (MI) was determined chiefly by raised CKMB levels ( $>5$ times the upper limit of normal and $>10 \%$ of total CPK levels) in blood associated with development of new electrocardiographic changes after surgery and/or new regional wall motion abnormality on postoperative echocardiogram and/or angiographic evidence of new graft or native vessel occlusion. Other recorded parameters are shown in Table 1.

\section{Surgical technique}

A standard median sternotomy was used to perform all surgeries. The technique used to harvest grafts was at the discretion of the operating surgeon. Most ITAs were harvested in a skeletonized manner, whereas the radial arteries (RA) were always harvested in a pedicled fashion. The RAs and saphenous vein grafts (SVG) were commonly harvested by an open technique and occasionally endoscopically. Various graft configurations were used ranging from in-situ bilateral ITAs, to Y/T-anastomoses (between two ITAs or an ITA and a RA or rarely, a SVG), to grafts anastomosed to the ascending aorta using a sidebiting clamp or proximal anastomotic devices, depending on the anatomy and severity of coronary artery disease (CAD). An activated clotting time greater than 300 seconds was maintained throughout the operation. The $\mathrm{Y} / \mathrm{T}$-anastomoses were most often performed prior to 
Table 1 Demographic characteristics of patients operated on during the three time cohorts

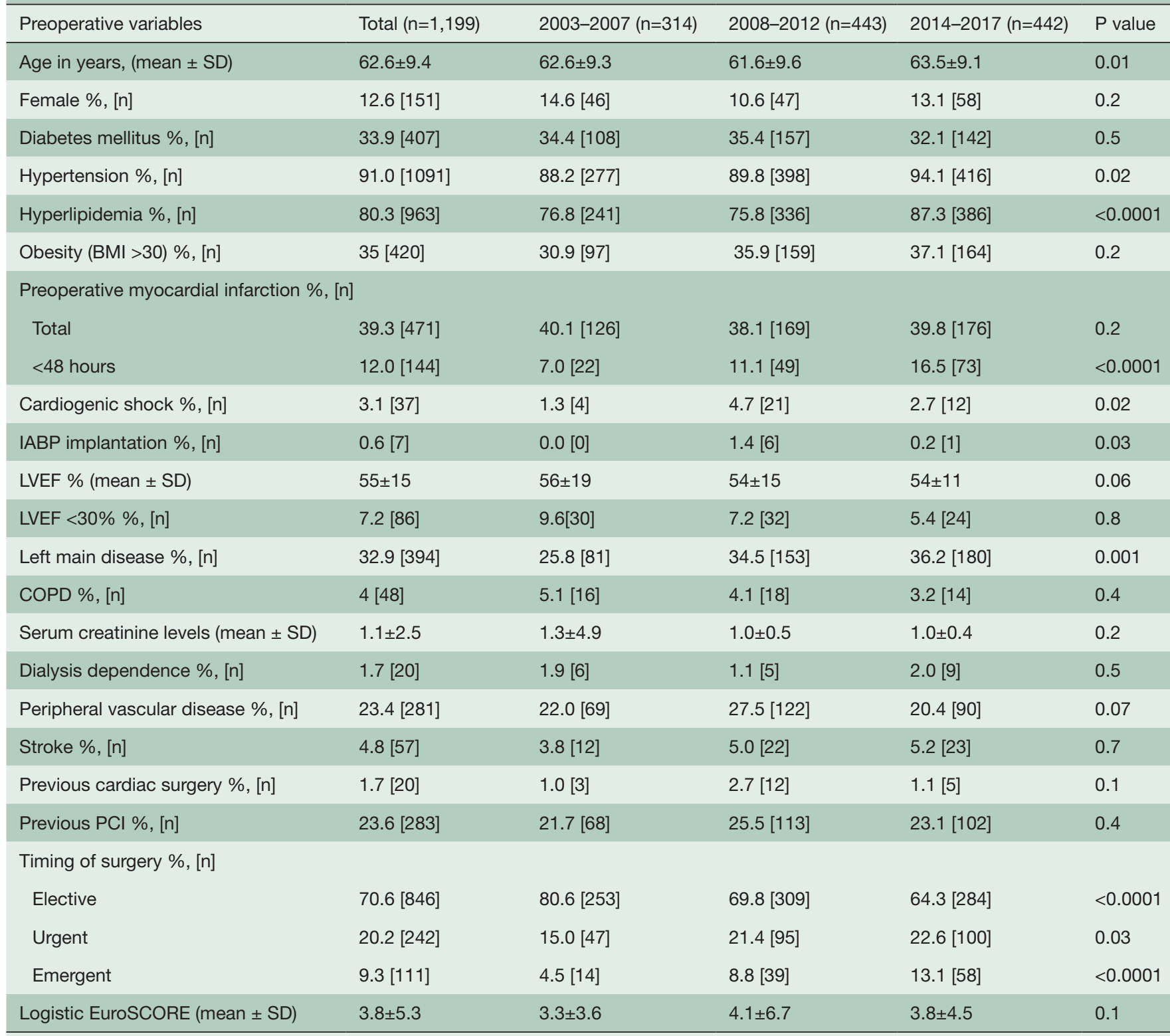

$\mathrm{SD}$, standard deviation; BMI, body mass index; IABP, intra-aortic balloon pump; LVEF, left ventricular ejection fraction; COPD, chronic obstructive pulmonary disease; $\mathrm{PCl}$, percutaneous coronary intervention.

distal coronary anastomoses. The SVG was used in a Y-configuration as the last option only in very old patients and when an adequate size match existed between itself and the ITA. The anastomotic area stabilization was achieved by one of the commercially available mechanical suction stabilizers. A heart positioner was occasionally used in patients with massively dilated and poorly functioning ventricles or mild to moderate mitral regurgitation. A pledgeted 4.0 polypropylene or silicon loop was used to occlude the target vessel proximal to the anastomotic site. A shunt was used for most anastomoses, which were performed with 7-0 or 8-0 polypropylene sutures. The left ITA to left anterior descending artery (LAD) anastomosis was almost always performed first. Exceptions were patients in whom the diagonal was grafted by the left ITA as a sequential anastomosis or the LAD was the only 


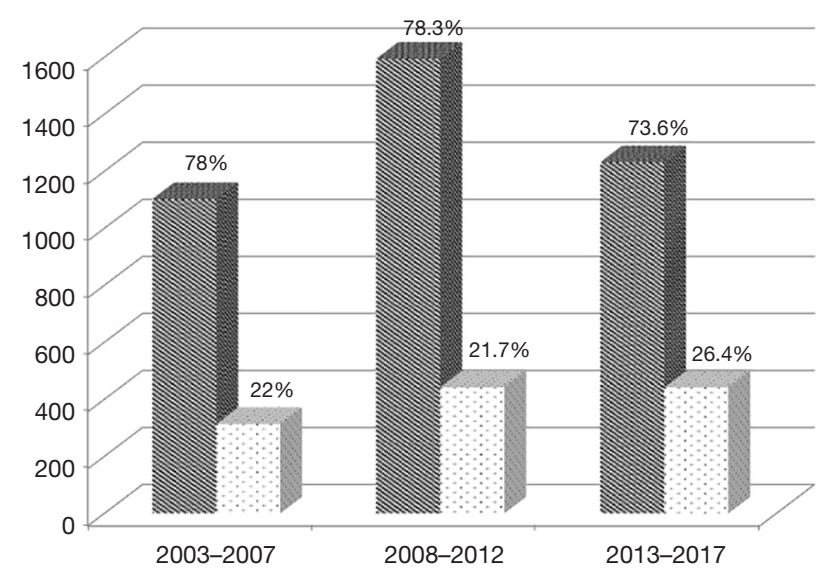

Figure 1 Proportion of patients undergoing off-pump CABG with bilateral ITAs (BITA) during the three time-cohorts (slashes: offpump CABG without BITA; dots: off-pump CABG with BITA). $\mathrm{CABG}$, coronary artery bypass graft; ITA, internal thoracic arteries.

collateralizing artery.

After the operation, oral calcium- channel blockers or pentaerythrityl tetranitrate were prescribed to patients who received RA conduits and continued for 6 months. Antiplatelet therapy included aspirin at $100 \mathrm{mg} / \mathrm{d}$ (recommended for indefinite use) and $\mathrm{P} 2 \mathrm{Y}_{12}$ inhibitors in patients with recent $\mathrm{MI}$, endarterectomies or diffuse CAD for 6-12 months.

\section{Statistical analysis}

Continuous variables are expressed as mean $\pm \mathrm{SD}$, categorical data as proportions. Categorical variables were compared using chi-square test; independent continuous variables and laboratory values were compared by 2 -tailed Student's $t$-test or Mann-Whitney-U-test as appropriate at a level of significance of $\mathrm{P}<0.05$. Comparison of dependent variables was performed by Wilcoxon-test. Due to the small number of perioperative events, we refrained from performing a multivariate regression analysis. Kaplan Meier curves were used to demonstrate 5- and 10-year survival and Cox regression analysis was used to define the predictors of late mortality. The statistical analysis was performed using SPSS 17.0 (Chicago, IL, USA) and Microsoft Excel.

\section{Follow-up}

Follow-up was performed yearly by personal contact, mailed questionnaire, or by phone contact with patients and family members, with supplemental information supplied by family physicians and referring cardiologists until 2012 . Thereafter, it was irregularly performed.

\section{Results}

\section{Demographic characteristics}

A total of 1,199 patients underwent isolated off-pump CABG with bilateral ITAs at the Leipzig Heart Center, University of Leipzig over a 15 -year period between January 2003 and December 2017. Of these, 314 were operated upon between 2003 and 2007, 443 from 2008 to 2012, and 442 between 2013 and 2017. The utilization of bilateral ITAs in off-pump CABG significantly increased in the last 5 years in comparison to the first two time cohorts of the study period $(\mathrm{P}=0.002)$ (Figure 1). The demographic characteristics of patients undergoing surgery during the three time periods are depicted in Table 1 . The mean age of patients receiving bilateral ITAs significantly increased in the most recent time cohort. A similar trend was also observed with regards to patients with a higher BMI. The percentage of diabetic patients undergoing bilateral ITA grafting remained constant over the time period of this study. Bilateral ITAs were also more frequently used in patients with left main disease in the last two cohorts. A steady rise in the utilization of bilateral ITAs was also noted in urgent and emergent situations. Nonetheless, the overall risk profile of patients undergoing off-pump CABG with bilateral ITAs during the three time-intervals was relatively low, as depicted by the mean EuroSCOREs.

\section{Intraoperative data}

Intraoperative details are listed in Table 2. The average number of grafts performed per patient remained constant over 15 years. The use of RA conduits as additional grafts decreased significantly over time, whereas a significant rise in SVG use was observed. There was a significant reduction in the number of proximal aortic anastomoses and a relative increase in the performance of $\mathrm{Y}$-anastomoses as an inflow source in the most recent time-cohort. The last two time-cohorts demonstrated a significant increase in the percentage of patients with incomplete revascularization, even though the mean number of distal anastomoses was the highest in the last time cohort.

\section{Postoperative outcomes}

The commonest postoperative complications and their 


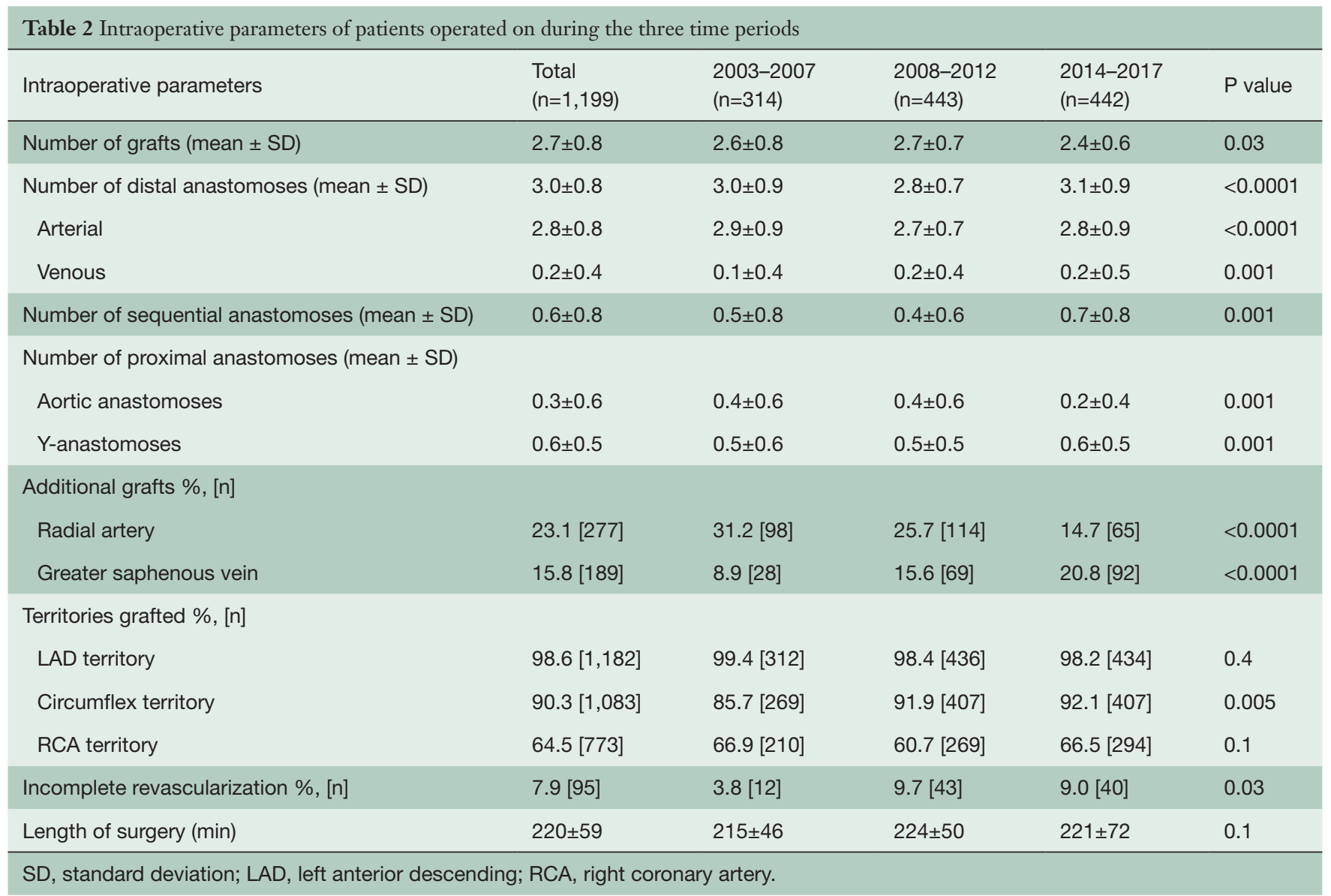

incidences are presented in Table 3. Thirty-day mortality was $0.6 \%$ and remained unchanged throughout the study period. Similarly, there was no difference in the incidence of postoperative low cardiac output syndrome, the requirement of intra-aortic balloon pump or extracorporeal membrane oxygenation, re-exploration for bleeding, or MI. The occurrence of stroke rate, however, was significantly lower in the two most recent time-cohorts. The overall incidence of deep sternal wound infections was $0.7 \%$ and was marginally higher in the last time-cohort.

\section{Follow-up}

Overall survival for the entire cohort of 1,199 patients was $92.9 \% \pm 1 \%$ and $78.9 \% \pm 4 \%$ at 5 - and 10 -year follow-up, respectively (Figure 2). Cox regression analysis revealed that age at surgery [odds ratio (OR): $1.1 ; 95 \%$ confidence interval (CI): $1.07-1.13 ; \mathrm{P}<0.0001]$ and peripheral vascular disease (OR: 1.7; 95\% CI: 1.06-2.62; $\mathrm{P}=0.03$ ) were independent predictors of late mortality and good preoperative left ventricular ejection fraction (OR: 0.9; 95\% CI: $0.96-0.98 ; \mathrm{P}<0.0001)$ had a protective effect.

\section{Discussion}

The overall 30-day mortality in the present study was extremely low at $0.6 \%$. It remained constant throughout the period of the study (Table 3) with no differences observed between the three time-cohorts. Another key finding was the low perioperative stroke rate of $0.6 \%$ observed in the present series, which demonstrated a significant reduction during the last decade of the study. The third important observation was the small number of patients who developed deep sternal wound infections. This dreaded complication, which apparently occurs more frequently following bilateral ITA harvest, was noted in $0.7 \%$ of patients in the whole cohort. No major temporal differences were recorded. Finally, the long-term survival 


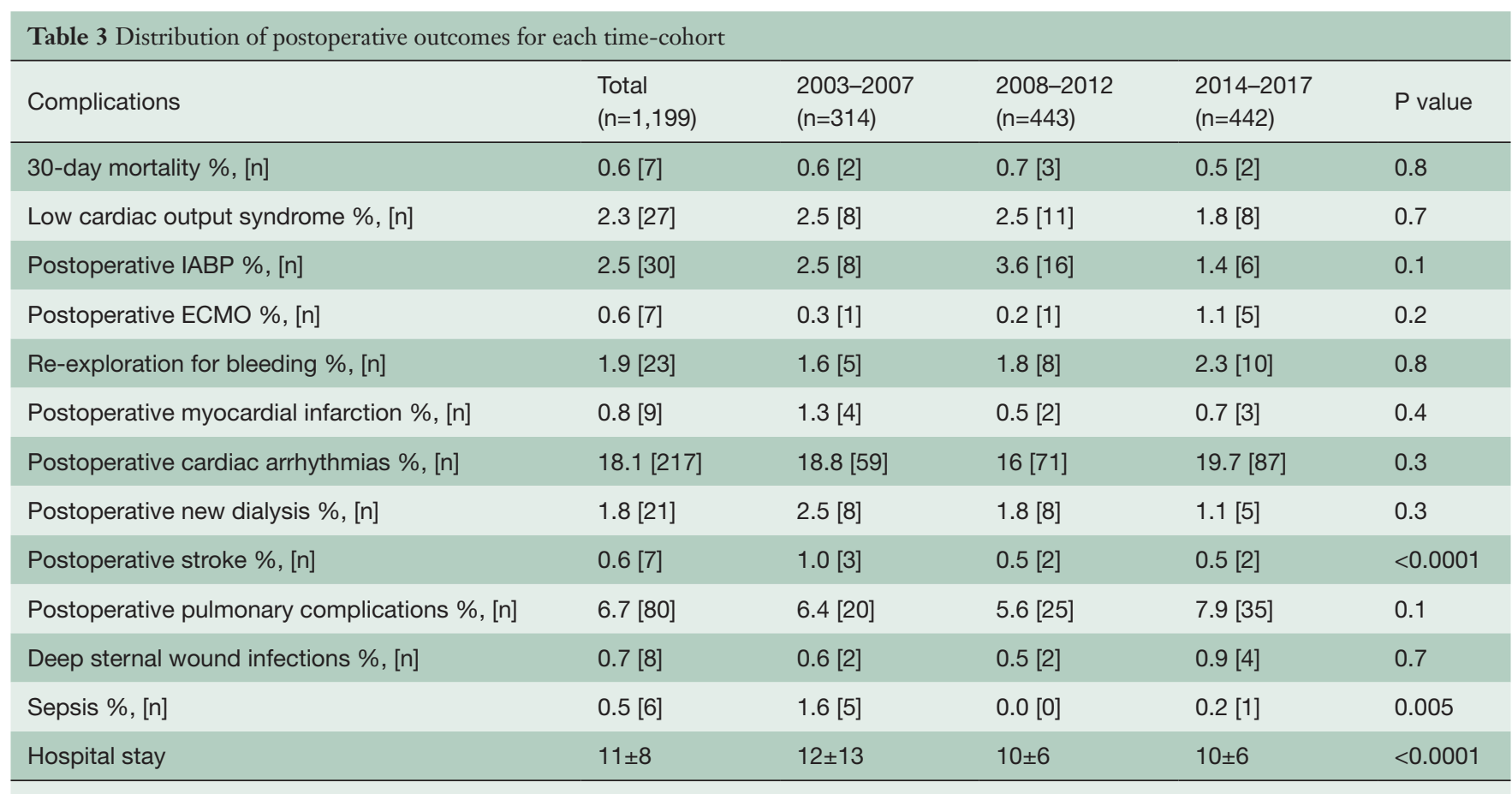

IABP, intra-aortic balloon pump; ECMO, extracorporeal membrane oxygenation.

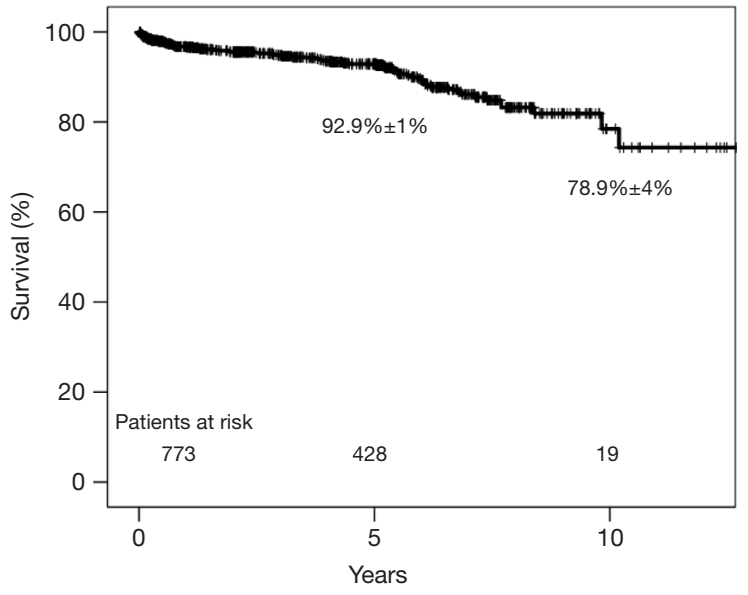

Figure 2 Kaplan-Meier curve demonstrating survival for all patients included in the study.

of patients undergoing off-pump CABG with bilateral ITAs was excellent, being greater than $90 \%$ and $75 \%$ at 5 and 10 years following surgery, respectively. Despite the excellent results, less than a quarter of the patients undergoing off-pump CABG received bilateral ITAs, though a significant increment from $22 \%$ to $26.4 \%$ was observed between the first and last time-cohorts. The reluctance in using bilateral ITAs is usually multifactorial, ranging from being more time consuming and technically challenging to the greater possibility of development of sternal wound infections. Nevertheless, the proportion of off-pump CABG patients who received bilateral ITAs at our institution was higher than the average in Europe (20\%) and much higher than that in the United States (5\%) (16).

Our 30-day mortality was less than half of that observed in off-pump CABG patients in the ART trial (1.4\%) who received bilateral ITAs (15) and a quarter of that reported by the CORONARY trial investigators for patients undergoing off-pump CABG (2.5\%) (17). This could be due to selection bias and the extensive experience of selected surgeons in off-pump bilateral ITA grafting. Nevertheless, our mortality also compares favorably with a report of 957 patients (1.7\% 30-day mortality in bilateral ITA offpump CABG patients) undergoing off-pump CABG with single or bilateral ITAs at a center well known for off-pump CABG (18). Most of the preoperative characteristics were similar to our patient cohort; however, nearly $20 \%$ of their patients had congestive heart failure and $15.3 \%$ were operated on emergently. Although insignificant, the mortality in our series was the lowest in the most recent time cohort, in spite of a significant increase in the age of 
patients, prevalence of left main disease, and the higher number of urgent and emergent surgeries performed (Table 1). This can be attributed to the rising experience of the entire operating room team and postoperative anesthesia and intensive care units.

Apart from mortality, the low perioperative stroke rate $(0.6 \%)$ for the whole cohort is also quite promising in favor of off-pump CABG. A significant reduction in the stroke rate $(0.5 \%)$ was observed in the two most recent time cohorts as compared to the initial 5 years of our study. Postoperative stroke has been the Achilles heel of CABG, which was particularly highlighted by the SYNTAX trial. The 30-day stroke rate in the SYNTAX trial was reported as $1 \%$ (19). Causes of stroke following CABG are multifactorial. The extent of aortic manipulation, which results in dislodgement of atheroemboli, has been known to have a significant impact on perioperative CVAs. A recent study comparing "anaortic" or "no touch aorta" CABG with clampless off-pump (PAS-Port device) and conventional on-pump CABG revealed a significantly lower stroke rate in favor of anaortic CABG $(0.5 \%)$ as compared to the latter two techniques (1\% and $1.2 \%$, respectively) (20). A reduction in aortic manipulation as evidenced by a drop in mean number of proximal aortic anastomoses and an increase in anaortic CABG (Table 2) could be one of the factors responsible for the temporal reduction in the stroke rate in our series, because some reports have demonstrated that aortic-clamping during off-pump CABG is associated with similar stroke rates to on-pump CABG $(21,22)$. Another advantage of off-pump CABG is the lower rate of postoperative atrial fibrillation/flutter, which could influence neurological outcomes positively (23). The incidence of all postoperative arrhythmias in our series was $18 \%$, which is remarkably lower than what is commonly reported following on-pump CABG (24). Off-pump CABG has been known to be associated with hypercoagulability, which has been attributed to surgical trauma and obligatory periods of warm ischemia during surgery (25). One can assume that optimization of perioperative antiplatelet therapy would result in a further reduction in embolic neurologic complications. However, when compared with aspirin alone, dual antiplatelet therapy with clopidogrel was not associated with a significant reduction of adverse cardiac and cerebrovascular events at 1 year following CABG in the ART trial (26).

Another important complication to be considered in patients undergoing CABG with bilateral ITAs is deep sternal wound infection, which is one of the major deterrents for its use by surgeons, especially in patients with insulin dependent diabetes mellitus, obesity, longterm steroid use, or dialysis dependence. In the ART trial, patients in the single ITA group $(0.6 \%)$ had a lower incidence of sternal wound reconstruction than the bilateral ITA group (1.9\%) (27). However, when stratified according to the harvest technique, the rate of severe sternal wound complications at 1 year following surgery dropped from 5.7\% (OR: 1.80) for the pedicled bilateral ITAs to $3.7 \%$ (OR: 1.00) for the skeletonized bilateral ITAs, which was similar to that for the pedicled single ITA (3.3\%). This could probably be due to considerably less acute sternal ischemia (28) and thereby less damage to tissue microcirculation in the middle and lower retrosternal area following ITA skeletonization (29), which has been unequivocally shown by single-photon emission computed tomography of the sternum after left ITA harvest (30). These results are further supported by a large metaanalysis comparing outcomes of 122,465 diabetic patients undergoing single ITAs with those who received 3,770 bilateral ITAs (31). The significant difference in the rate of deep sternal wound infection observed between single and bilateral ITAs disappeared when the analysis was restricted to patients undergoing skeletonized ITAs. This could probably explain the low rate of deep sternal wound infection in the current series (Table 3). Almost all surgeons at our institute use the skeletonized technique when performing bilateral ITA harvest. Our results are comparable to those $(0.9 \%)$ reported by Kinoshita et al. for patients undergoing off-pump CABG with bilateral skeletonized ITAs (32).

The single most important benefit of using bilateral ITAs is the superior long-term survival, which has been demonstrated by several observational studies $(7,8,13)$ and meta-analyses (9-11). However, long-term survival following off-pump CABG has always been a matter of debate. One of the most recent meta-analysis involving over 1.2 million patients investigated long-term mortality in approximately 91,000 patients (33). They revealed a relative risk of 1.1 for mortality at 5 and 10 years following off-pump CABG with a statistically significant $15 \%$ greater risk of death. This long-term disadvantage was more pronounced with adjusted observational studies than randomized clinical trials. Therefore, the long-term benefit of bilateral ITAs may be offset by off-pump CABG and a major factor responsible for it may be incomplete revascularization. Benedetto et al. showed that incomplete revascularization was associated with a higher risk of death after off-pump CABG (HR 1.26; 95\% CI: 1.05-1.49) 
regardless the extent of incomplete revascularization i.e., failure to revascularize one or two vessels (34). Incomplete revascularization in off-pump CABG is more commonly due to technical difficulties and inexperience of surgeons, which often leads to aversion from grafting vessels of adequate size and quality supplying large areas of viable myocardium, which can negatively impact early and late outcomes. The 5 - and 10-year survival in our series was excellent and can be attributed to the use of bilateral ITAs and a lower rate of incomplete revascularization ( $8 \%$ ), which was $22 \%$ in the propensity-matched analysis by Benedetto et al. (34) and as high as $36.8 \%$ in the CABG arm of the SYNTAX trial (35). Additionally, a greater number of arterial anastomoses and the lesser utilization of veins would have also contributed to the better long-term survival (Table 2).

\section{Study limitations}

Our study has several limitations. First, it is a retrospective study and is, therefore, subject to all limitations inherent with such studies. The selection bias in such a series can be profound, as patients with insulin-dependent diabetes mellitus, morbid obesity, severe chronic obstructive pulmonary disease, renal failure, or long-term steroid therapy would have been inevitably excluded from the study as such comorbidities and risk factors would pose a greater hazard to development of sternal wound infections following bilateral ITA grafting. Contrarily, being an offpump CABG study, several patients at a higher risk of stroke due to aortic calcification would have been included in the study. Therefore, our study would at least give insight into the type of patients who would benefit most from bilateral ITAs and an off-pump technique.

\section{Conclusions}

Off-pump CABG with bilateral ITAs is a safe operation and is associated with a low mortality and morbidity. Skeletonized harvest of both ITAs reduces the likelihood of deep sternal wound infections. The long-term survival of patients undergoing bilateral ITAs is excellent. Being safe and efficacious, surgeons should strive to use bilateral ITAs during off-pump CABG.

\section{Acknowledgements}

None.

\section{Footnote}

Conflicts of Interest: The authors have no conflicts of interest to declare.

\section{References}

1. Shroyer AL, Hattler B, Wagner TH, et al. Five-Year Outcomes after On-Pump and Off-Pump CoronaryArtery Bypass. N Engl J Med 2017;377:623-32.

2. Lamy A, Devereaux PJ, Prabhakaran D, et al. Five-year outcomes after off-pump or on-pump coronary-artery bypass grafting. N Engl J Med 2016;375:2359-68.

3. Puskas JD, Williams WH, Mahoney EM, et al. Off-pump vs conventional coronary artery bypass grafting: early and 1-year graft patency, cost, and quality-oflife outcomes: a randomized trial. JAMA 2004;291:1841-9.

4. Straka Z, Widimsky P, Jirasek K, et al. Off-pump versus on-pump coronary surgery: final results from a prospective randomized study PRAGUE-4. Ann Thorac Surg 2004;77:789-93.

5. Houlind K, Kjeldsen BJ, Madsen SN, et al. On-pump versus off-pump coronary artery bypass surgery in elderly patients: results from the Danish On-pump versus Offpump Randomization Study. Circulation 2012;125:2431-9.

6. Diegeler A, Börgermann J, Kappert U, et al. Off-pump versus on-pump coronary artery bypass grafting in elderly patients. N Engl J Med 2013;368:1189-98.

7. Lytle BW, Blackstone EH, Loop FD, et al. Two internal thoracic artery grafts are better than one. J Thorac Cardiovasc Surg 1999;117:855-72.

8. Lytle BW, Blackstone EH, Sabik JF, et al. The effect of bilateral internal thoracic artery grafting on survival during 20 postoperative years, Ann Thorac Surg 2004;78:2005-12.

9. Taggart DP, D'Amico R, Altman DG. The effect of arterial revascularization on survival: a systematic review of studies comparing bilateral and single internal mammary arteries. Lancet. 2001;358:870-5.

10. Weiss AJ, Zhao S, Tian DH, et al. A meta-analysis comparing bilateral internal mammary artery with left internal mammary artery for coronary artery bypass grafting. Ann Cardiothorac Surg 2013;2:390-400.

11. Yi G, Shine B, Rehman SM. Effect of Bilateral Internal Mammary Artery Grafts on Long-Term Survival A MetaAnalysis Approach. Circulation 2014;130:539-45.

12. Dorman MJ, Kurlansky PA, Traad EA, et al. Bilateral internal mammary artery grafting enhances survival in 
diabetic patients: a 30-year follow-up of propensity scorematched cohorts. Circulation 2012;126:2935-42.

13. Kurlansky PA, Traad EA, Dorman MJ, et al. Thirty-Year Follow-Up Defines Survival Benefit for Second Internal Mammary Artery in Propensity-Matched Groups, Ann Thorac Surg 2010;90:101-8.

14. Taggart DP, Altman DG, Gray AM, et al. Randomized Trial of Bilateral versus Single Internal-Thoracic-Artery Grafts. N Engl J Med 2016;375:2540-9.

15. Taggart DP, Altman DG, Gray AM, et al. Effects of onpump and off-pump surgery in the Arterial Revascularization Trial. Eur J Cardiothorac Surg 2015;47:1059-65.

16. Falk V. Coronary artery bypass grafting with bilateral internal thoracic arteries. Heart 2013;99:821.

17. Lamy A, Devereaux PJ, Prabhakaran D, et al. Off-pump or on-pump coronary-artery bypass grafting at 30 days. $\mathrm{N}$ Engl J Med 2012;366:1489-97.

18. Pevni D, Ben-Gal Y, Mohr R, et al. One or Two Internal Thoracic Grafts? Long-Term Follow-Up of 957 OffPump Coronary Bypass Surgeries. Ann Thorac Surg 2017;104:70-7.

19. Mack MJ, Head SJ, Holmes DR Jr, et al. Analysis of stroke occurring in the SYNTAX trial comparing coronary artery bypass surgery and percutaneous coronary intervention in the treatment of complex coronary artery disease. JACC Cardiovasc Interv 2013;6:344-54.

20. Furukawa N, Kuss O, Preindl K, et al. Anaortic off-pump versus clampless off-pump using the PAS-Port device versus conventional coronary artery bypass grafting: midterm results from a matched propensity score analysis of 5422 unselected patients. Eur J Cardiothorac Surg 2017;52:760-767.

21. Kim KB, Kang CH, Chang WI, et al. Off-pump coronary artery bypass with complete avoidance of aortic manipulation. Ann Thorac Surg 2002;74:S1377-82.

22. Kotoh K, Fukahara K, Doi T, et al. Predictors of early postoperative cerebral infarction after isolated offpump coronary artery bypass grafting. Ann Thorac Surg 2007;83:1679-83.

23. Kuss O, von Salviati B, Börgermann J. Off-pump versus on-pump coronary artery bypass grafting: a systematic review and meta-analysis of propensity score analyses. J Thorac Cardiovasc Surg 2010;140:829-35.

24. El-Chami MF, Kilgo P, Thourani V, et al. New-onset atrial fibrillation predicts long-term mortality after coronary artery bypass graft. J Am Coll Cardiol 2010;5 5:1370-6.

25. Kon ZN, Brown EN, Grant MC, et al. Warm ischemia provokes inflammation and regional hypercoagulability within the heart during off-pump coronary artery bypass: a possible target for serine protease inhibition. Eur J Cardiothorac Surg 2008;33:215-21.

26. Benedetto U, Altman DG, Gerry S, et al. Impact of dual antiplatelet therapy after coronary artery bypass surgery on 1-year outcomes in the Arterial Revascularization Trial. Eur J Cardiothorac Surg 2017;52:456-61.

27. Benedetto U, Altman DG, Gerry S, et al. Pedicled and skeletonized single and bilateral internal thoracic artery grafts and the incidence of sternal wound complications: Insights from the Arterial Revascularization Trial. J Thorac Cardiovasc Surg 2016;152:270-6.

28. Graeber GM. Harvesting of the internal mammary artery and the healing median sternotomy, Ann Thorac Surg 1992;53:7-8.

29. Kamiya H, Akhyari P, Martens A, et al. Sternal microcirculation after skeletonized versus pedicled harvesting of the internal thoracic artery: a randomized study. J Thorac Cardiovasc Surg 2008;135:32-7.

30. Cohen AJ, Lockman J, Lorberboym M, et al. Assessment of sternal vascularity with single photon emission computed tomography after harvesting of the internal thoracic artery. J Thorac Cardiovasc Surg 1999;118:496-502.

31. Deo SV, Shah IK, Dunlay SM, et al. Bilateral internal thoracic artery harvest and deep sternal wound infection in diabetic patients. Ann Thorac Surg 2013;95:862-9.

32. Kinoshita T, Asai T, Suzuki T, et al. Off-pump bilateral skeletonized internal thoracic artery grafting in elderly patients. Ann Thorac Surg 2012;93:531-6.

33. Filardo G, Hamman BL, da Graca B, et al. Efficacy and effectiveness of on- versus off-pump coronary artery bypass grafting: A meta-analysis of mortality and survival. J Thorac Cardiovasc Surg 2018;155:172-179.e5.

34. Benedetto U, Gaudino M, Di Franco A, et al. Incomplete revascularization and long-term survival after coronary artery bypass surgery. Int J Cardiol 2018;254:59-63.

35. Head SJ, Mack MJ, Holmes DR Jr, et al. Incidence, predictors and outcomes of incomplete revascularization after percutaneous coronary intervention and coronary artery bypass grafting: a subgroup analysis of 3-year SYNTAX data, Eur. J Cardiothorac Surg 2012;41:535-41.

Cite this article as: Davierwala PM, Leontyev S, Garbade J Lehmann S, Holzhey D, Misfeld M, Borger MA. Off-pump coronary artery bypass surgery with bilateral internal thoracic arteries: the Leipzig experience. Ann Cardiothorac Surg 2018;7(4):483-491. doi: 10.21037/acs.2018.06.15 